\title{
Digital Manufacturing Certificate Toolkit: Adding Trust and Traceability to Product Data
}

\author{
Thomas Hedberg $^{1}$ and Sylvere Krima ${ }^{2}$ \\ ${ }^{1}$ National Institute of Standards and Technology, \\ Gaithersburg, MD 20899 \\ ${ }^{2}$ Engisis LLC, \\ Bethesda, MD 20817
}

thomas.hedberg@nist.gov

sylvere.krima@engisis.com

Software DOI: https://doi.org/10.18434/T4P30K

Software Version: 0.1

Key words: data traceability; digital signatures; trustworthiness.

Accepted: November 28, 2016

Published: November 29, 2016

https://doi.org/10.6028/jres.121.027

\section{Summary}

The NIST Digital Manufacturing Certificate (DMC) Toolkit is a toolkit designed specifically to provide certification - digital signature using software and hardware certificates and verification — of manufacturing related data. The DMC toolkit supports signature and validation of data in the following formats: ISO 10303-21 (STEP) [1], ISO 6983 (G-code) [2], ISO 32000 (PDF) [3] and 14739 (PRC, a.k.a. 3D PDF) [4], and Quality Information Framework (QIF) [5]. The project offers the Toolkit as a .NET API (written in C\#), a command-line tool, and a fully-functional demonstration application.

\section{Software Specifications}

\begin{tabular}{|l|l|}
\hline NIST Operating Unit(s) & Systems Engineering Group, Engineering Laboratory \\
\hline Category & Data certification and validation \\
\hline Targeted Users & $\begin{array}{l}\text { 1) Software developers who want to provide customers with the ability to digitally sign manufacturing-related } \\
\text { data within software systems. } \\
\text { 2) End-users who want to digitally sign manufacturing-related data independent of the software system used. }\end{array}$ \\
\hline Operating System(s) & Microsoft Windows only \\
\hline Programming Language & C\#.NET \\
\hline Inputs/Outputs & Inputs: product data file and digital certificate. Output: electronically signed product data file \\
\hline Documentation & Documentation available at https://doi.org/10.18434/T4P30K \\
\hline Accessibility & N/A \\
\hline Disclaimer & https://www.nist.gov/director/licensing \\
\hline
\end{tabular}




\section{Methods}

This software provides source-code, an executable file with graphical user-interface, and a command-line tool for digitally signing manufacturing-related data. The user of this software may use any of the supplied options that best meet the user's need to digitally sign data. A general overview of the methodology implemented in the toolkit is available in Ref. [6]. More information and details on the specific use of each method is available at https://doi.org/10.18434/T4P30K.

\section{References}

[1] International Organization for Standardization (2002) ISO 10303-21:2002 — Industrial automation systems and integration -- Product data representation and exchange -- Part 21: Implementation methods: Clear text encoding of the exchange structure (International Organization for Standardization, Geneva, Switzerland).

[2] International Organization for Standardization (2009) ISO 6983-1:2009 - Automation systems and integration -- Numerical control of machines -- Program format and definitions of address words -- Part 1: Data format for positioning, line motion and contouring control systems (International Organization for Standardization, Geneva, Switzerland).

[3] International Organization for Standardization (2008) ISO 32000-1:2008 - Document management -- Portable document format -- Part 1: $P D F 1.7$ (International Organization for Standardization, Geneva, Switzerland).

[4] International Organization for Standardization (2014) ISO 14739-1:2014 - Document management -- 3D use of Product Representation Compact (PRC) format -- Part 1: PRC 10001 (International Organization for Standardization, Geneva, Switzerland).

[5] Dimensional Metrology Standards Consortium (2015) Quality Insurance Framework (QIF). Available http://qifstandards.org/. Accessed November 28, 2016.

[6] Hedberg JTD, Krima S, Camelio JA (2016) Embedding X.509 Digital Certificates in Three-Dimensional Models for Authentication, Authorization, and Traceability of Product Data. Journal of Computing and Information Science in Engineering 17(1):011008. https://doi.org/10.1115/1.4034131

About the authors: Tom Hedberg is a mechanical engineering researcher at NIST. He is the project co-leader of the Digital Thread for Smart Manufacturing project and the co-coordinator of the Smart Manufacturing Systems Test Bed. His research areas focus on the integration of model-based methods for design and manufacturing using product lifecycle management practices.

Sylvere Krima is a researcher at Engisis L.L.C. and an associate researcher at NIST. He has been collaborating with the Systems Engineering Group, developing certification and traceability of product data methods to support the digital thread.

The National Institute of Standards and Technology is an agency of the U.S. Department of Commerce. 